\title{
Magnitude and Determinants of Primary Cesarean Section Among Women Who Gave Birth in Shire, Northern Ethiopia
}

This article was published in the following Dove Press journal: Open Access Surgery

\author{
Addisu Alehegn Alemu (D) \\ Liknaw Bewket Zeleke (D) \\ College of Health Sciences, Debre \\ Markos University, Debre Markos, \\ Ethiopia
}

Background: Cesarean section (CS) is a lifesaving medical intervention. It plays a vital role in decreasing maternal mortality and morbidity rates. It is also an indicator of maternal health services quality of a country. CS practice has been rising regardless of the medical condition, age, race, or gestational age. However, it is associated with many complications compared with vaginal deliveries, particularly in developing countries. Therefore, the aim of this study was to assess the magnitude and determinants of primary cesarean section among women who gave birth in Suhul General Hospital, Shire town, Northern Ethiopia.

Methods: Institutional cross-sectional study was conducted from September 19 to October 20, 2017, among women who gave birth between September and August 2016 in Suhul General Public Hospital. Data were entered into EPI Info version 7 and exported to SPSS version 25 for analysis. Bivariate and multivariate logistic regressions were examined to assess the association between outcome and independent variables. Finally, variables with p-value less than 0.05 on multivariate logistic regression analysis were considered as significantly associated.

Results: The magnitude of primary CS was $20.2 \%$. The main indication for CS was nonreassuring fetal heartbeat pattern (NRFHRP) (32.2\%). Women who had been augmented were 3.14 times more likely to undergo primary CS than those who had not (adjusted odds ratio $(\mathrm{AOR})=3.14 ; 95 \% \mathrm{CI}: 1.49,6.57)$. Women who had pregnancy-induced hypertension were 3.1 times more likely to undergo primary $\mathrm{CS}$ than those who had not $(\mathrm{AOR}=3.10 ; 95 \%$ CI: $1.23,7.83)$. Additionally, women who gave birth of $\geq 4000$ gm newborns were 11 times $(\mathrm{AOR}=11 ; 95 \% \mathrm{CI}: 2.30,57.51)$ more likely to undergo primary $\mathrm{CS}$ than those who gave birth 2500-3999 gm of newborns. Moreover, women with unknown gestational age were 5.83 times $(\mathrm{AOR}=5.83 ; 95 \% \mathrm{CI}: 2.37,14.31)$ more likely to undergo primary $\mathrm{CS}$ than women whose gestational age was $37-42$ weeks.

Conclusion: The magnitude of the primary cesarean section in this study was high. Gestational age, augmentations, PIH, and birth weight were significant determinants of primary CS. Objective decisions should be practiced to reduce the magnitude of the primary caesarean section.

Keywords: primary cesarean section, magnitude, determinants, Ethiopia

\section{Background}

Cesarean section (CS) is the birth of a viable fetus through an incision in the abdominal and uterine walls. It does not include removal of the fetus from the abdominal cavity in the case of uterine rupture or abdominal pregnancy. It is categorized either primary (first-time delivery) or repeated (after a previous
Correspondence: Addisu Alehegn Alemu College of Health Sciences, Debre Markos University, P.O.Box: 269, Debre Markos, Ethiopia

Email addisua4@gmail.com
Open Access Surgery 2020:13 53-59 
cesarean section/s). ${ }^{1,2}$ It is the most common obstetric operative procedure all over the world and constitutes $15 \%$ of all deliveries. There is a growing concern that it has been rising regardless of a medical condition, age, race, or gestational age. The high incidence of cesarean delivery in developed countries is due to better anesthetics, different antimicrobial agents, and blood transfusion facilities. Additionally, there is higher public interest in developed countries to avoid fetal complications and acceptance by most of the couples to complete their family with one or two children. However, the reasons for the recent increase in the rate of primary cesarean section are different in developing countries. ${ }^{3-5}$

CS is a major surgery that can cause significant, and sometimes permanent, complications particularly in settings that lack the facilities and capacity to properly conduct safe surgery and treat surgical complications. The main complications of CS include risk of blood transfusion, infections, and hysterectomy for women, and risk of respiratory distress, hypoglycemia, and breastfeeding complications for the neonates. Moreover, a uterine scar due to CS is associated with uterine rupture, placenta accreta, and placenta Previa in a subsequent pregnancy. Therefore, primary CS determines the future obstetric course of a woman. ${ }^{2,3,5-12}$

Though various reasons have been suggested for the increment of total CS rate globally, unjustified primary CS has been identified as one of the main reasons. ${ }^{5,13,14}$ Therefore, this study was aimed to identify the magnitude and factors associated with primary cesarean section among women who gave birth in Suhul General Hospital, Shire town, Northern Ethiopia.

\section{Methods}

\section{Study Design, Area and Period}

An institutional cross-sectional study was conducted from September 19 to October 20, 2017. The study was conducted among women who gave birth between September and August 2016 in Suhul General Public Hospital which is found in Shire town. Shire is the administrative town of the North-Western zone of Tigray regional state, and located about $1080 \mathrm{~km}$ north of Addis Ababa, the capital city of Ethiopia. The town consists of one general public hospital and 2 health centers and around 10 private health clinics. The hospital consists of different wards, surgical, medical, and maternity wards.

\section{Study Population}

All women's cards which showed birth after a gestational age of viability ( $\geq 28$ weeks) at Suhul General Hospital in the reference period were included in the study. Women with a history of operation for uterine rupture and previous CS were excluded from the study.

\section{Sample Size Determination and Sampling Procedure}

The sample size was computed using single population proportion formula with a $95 \%$ confidence level, $5 \%$ margin of error, and $50 \%$ proportion of primary CS. After considering $10 \%$ for incomplete data, the final sample size was 422. A systematic random sampling technique was applied by taking the list of all mothers who gave birth at the hospital in the reference period as a sampling frame. There were a total of 2316 deliveries. Based on this, the skip interval (k) was 6. The starting point was selected randomly by lottery method.

\section{Data Collection and Quality Control}

Data were collected using a structured checklist prepared for this purpose adapted from different works of literature. The checklist included socio-demographic characteristics (age, residence, referral), fetal characteristics (presentation, number, lie and birth weight) and obstetrical procedures (induction, argumentation, and instrumentation). Similarly, bad obstetrical and gynecological factors (history of stillbirth, early neonatal death (END), history of infertility and history of fistula repaired), chronic medical illness (DM, HTN and cardiac disease) and current obstetrical factors (parity, gestational age, fetal condition and $\mathrm{PIH}$ ) were considered through the checklist. Moreover, type of primary CS (Emergency and elective) was included in the checklist.

Data collection questionnaire were pretested among $5 \%$ of the sample size. Two days of training were given for data collectors before and after the pretest. The focus of the training was about the objectives of the study, the contents of the checklist's, data collection techniques, and ethical issues. Besides, there was a daily checking of the incompleteness and inconsistencies of checklists. The principal investigator and supervisors supervised the overall data collection procedure on daily basis. Data were collected by two trained midwives. 


\section{Definitions of Terms}

Primary CS rate: the number of births to women having a cesarean delivery per births to women without a previous cesarean regardless of parity. ${ }^{15,16}$

Emergency CS: when the operation is done due to unforeseen or acute obstetric emergencies. ${ }^{17,18}$

Elective CS: when the operation is done at a prearranged time to ensure the best quality of obstetrics, anesthesia, neonatal resuscitation, and nursing services. ${ }^{19,20}$

\section{Data Processing and Analysis}

The collected data were entered into Epi Info version 7.1 (Atlanta, GA) and exported to SPSS version 25 (Armonk, NY: IBM Corp) for statistical analysis. To explain the study population with relevant variables descriptive statistics (Frequencies, mean, SD, percentage) were used. Both bivariate and multivariate logistic regression were used to assess the association between outcome and explanatory variables. During analysis, those variables in bivariate analysis with a p-value of less than 0.05 were included in multivariate logistic regression. Finally, multivariate analysis was computed and variables with p-value less than 0.05 were considered as significantly associated. The associations and their strength were presented using odds ratios, $95 \%$ confidence interval, and $\mathrm{p}$ - value. The result of the analysis was presented using tables and texts.

\section{Results}

\section{Socio-Demographic Characteristics}

Four hundred women's cards, making $94.8 \%$ response rate, were included in this study. The age of the women ranged between 17 and 43 years with a mean age of 26 years and standard deviation (SD) \pm 5.3 . Two hundred twenty-three $(55.8 \%)$ of women were from urban and $177(44.2 \%)$ were from rural areas. From 64 (16\%) referral cases, 25 (39.1\%) were from primary hospital and general hospitals and $39(60.9 \%)$ were from health centers and health posts.

\section{Obstetrical, Gynecological and Medical Characteristics}

Out of all study participants, 273 (68.2\%) were multipara. Three hundred ninety-one (97.8\%) of women had antenatal care (ANC) follow up at least once for their last pregnancy. The gestational age for $313(78.2 \%)$ of study participants was between 37 and 42 weeks and it was unknown for 33 (8. 2\%). Two hundred ninety-six (74\%) of women delivered by spontaneous vaginal delivery (SVD), $23(5.8 \%)$ by instrumental assisted, and the remaining $81 \quad(20.2 \%)$ were delivered by Cesarean Section. Three hundred fifty $(87.5 \%)$ of women initiated labor spontaneously. Of these, 54 (15.4\%) were augmented. Twenty-four $(6 \%)$ women had history of chronic medical illness (Table 1).

\section{Indications of Primary CS}

The most frequent indications for primary cesarean section were NRFHP (32.1\%), CPD (18.5\%), and abnormal presentation (12. 3\%). Whereas, failed induction, cord prolapse, and PPROM+grand multipara each account two $(2.5 \%)$. The least frequent indications were severe IUGR

+ late-term pregnancy accounts one (1.24\%).

\section{Fetal Characteristics}

Three hundred eighty-three (95.8\%) of women had longitudinal fetal lie on admission to the maternity ward. Three hundred seventy-six (94\%) of fetuses were singleton and only one $(0.3 \%)$ was a triplet. Three hundred eighty-two $(95.5 \%)$ women gave birth to alive infant. Three hundred forty-nine (87.3\%) of newborn babies weigh between 2500 and 3999 gm, $42(10.4 \%)$ weigh $<2500$ gm and $9(2.3 \%)$ weigh $\geq 4000$ gm (Table 2).

\section{Determinants of Primary Caesarean Section}

Women who were augmented were 3.14 times $(\mathrm{AOR}=$ 3.14 ; $95 \%$ CI: $1.49,6.57)$ more likely to undergo primary CS than those who were not augmented. Women who had history of pregnancy-induced hypertension were 3.1 times $(\mathrm{AOR}=3.10 ; 95 \% \mathrm{CI}: 1.23,7.83)$ more likely to give birth with primary CS than those who had no history of PIH. Similarly, women who gave birth of infants $\geq 4000$ gm were 11 times $(\mathrm{AOR}=11 ; 95 \% \mathrm{CI}: 2.30,57.51)$ more likely to undergo primary CS than who gave birth 2500-3999 gm of a newborn. Moreover, women with unknown gestational age were 5.83 times $(\mathrm{AOR}=5.83$; $95 \%$ CI: $2.37,14.31)$ more likely to undergo primary CS than women with gestational age of $37-42$ weeks (Table 3).

\section{Discussion}

Nowadays institutional delivery for all pregnant women is a slogan in Ethiopia for safe delivery. The government is also implementing different strategies to avoid fetal and 
Table I Obstetric, Gynecological and Medical History of Mothers Who Gave Birth in Suhul General Hospital, Shire, Northern Ethiopia, $2017(n=400)$

\begin{tabular}{|c|c|c|}
\hline Characteristics & No & $\%$ \\
\hline \multicolumn{3}{|l|}{ Parity } \\
\hline Prim gravida & 127 & 31.8 \\
\hline Multi gravida & 273 & 68.2 \\
\hline \multicolumn{3}{|l|}{ ANC follow up } \\
\hline Yes & 391 & 97.8 \\
\hline No & 9 & 2.3 \\
\hline \multicolumn{3}{|l|}{ Onset of labor } \\
\hline Spontaneous & 350 & 92.3 \\
\hline Induced & 29 & 7.7 \\
\hline \multicolumn{3}{|l|}{ Augmented } \\
\hline Yes & 54 & 15.4 \\
\hline No & 296 & 84.6 \\
\hline \multicolumn{3}{|l|}{ Mode of delivery } \\
\hline SVD & 296 & 74 \\
\hline Instrumental & 23 & 5.8 \\
\hline CS & 81 & 20.2 \\
\hline \multicolumn{3}{|l|}{ Type of CS } \\
\hline Elective & 21 & 25.9 \\
\hline Emergency & 60 & 74.1 \\
\hline \multicolumn{3}{|l|}{ History of PIH } \\
\hline Yes & $4 I$ & 10.2 \\
\hline No & 359 & 89.8 \\
\hline \multicolumn{3}{|l|}{ History of still birth } \\
\hline Yes & 25 & 6.2 \\
\hline No & 375 & 93.8 \\
\hline \multicolumn{3}{|l|}{ History of END } \\
\hline Yes & 13 & 3.2 \\
\hline No & 387 & 96.8 \\
\hline \multicolumn{3}{|l|}{ History of infertility } \\
\hline Yes & 4 & 1 \\
\hline No & 396 & 99 \\
\hline \multicolumn{3}{|l|}{ History of fistula } \\
\hline Yes & 1 & 0.3 \\
\hline No & 399 & 99.7 \\
\hline \multicolumn{3}{|l|}{ History of chronic medical illness } \\
\hline Yes & 24 & 6 \\
\hline No & 376 & 94 \\
\hline \multicolumn{3}{|l|}{ Gestational age in weeks } \\
\hline$<37$ & 27 & 6.8 \\
\hline $37-42$ & 313 & 78.2 \\
\hline$>42$ & 27 & 6.8 \\
\hline Unknown & 33 & 8.2 \\
\hline
\end{tabular}

Table 2 Fetal Characteristics of Who Gave Birth in Suhul General Hospital, Shire, Northern Ethiopia, $2017(n=400)$

\begin{tabular}{|l|l|l|}
\hline Characteristics & No & $\%$ \\
\hline Fetal lie & 383 & \\
$\quad$ Longitudinal & 9 & 95.8 \\
Oblique & 8 & 2.2 \\
Transverse & & 2 \\
\hline Number of fetus & 376 & \\
Single & 23 & 94 \\
Twin & 1 & 5.7 \\
Triplet & & 0.3 \\
\hline Presentation of first twin & 21 & \\
Cephalic & 2 & 91.3 \\
Breech & & 8.7 \\
\hline Fetal condition & 382 & \\
Alive & 18 & 95.5 \\
Died & & 4.5 \\
\hline Birth weight & 42 & \\
$<2500$ gm & 349 & 8.4 \\
$2500-3999$ gm & 9 & 2.3 \\
\hline 4000 gm & & \\
\hline
\end{tabular}

maternal complications by giving free service for all pregnant women including cesarean section service. However, in many cases, the indications for cesarean section are doubtful where the proper fetal monitoring and assessment of the cases are lacking. Therefore, this study was conducted to determine the magnitude and factors associated with primary caesarean sections in Suhul General Hospital, northern Ethiopia.

The proportion of women who undergone primary cesarean section in this study was $20.2 \%$. It is almost similar to the study done in Saudi Arabia (21.6\%) but slightly lower than the study done in Florida and Louisiana (26.9\%). Moreover, it is much lower than the study done in India (68.4\%). This higher rate of cesarean section in India might be attributed to CS by patient choice, use of electronic fetal monitoring (EFM), and it was done in a tertiary hospital on primipara women only. The use of EFM has been directly associated with an increase in cesarean delivery. ${ }^{21}$ However, the current study was done in a general hospital where there was no use of EFM regardless of parity and there was no cesarean section done for the patient's preference. 
Table 3 Bivariate and Multivariate Analysis of Factors Associated with Primary Cesarean Section

\begin{tabular}{|c|c|c|c|c|}
\hline \multirow[t]{2}{*}{ Variables } & \multicolumn{2}{|c|}{$\begin{array}{l}\text { Primary } \\
\text { CS }\end{array}$} & \multicolumn{2}{|l|}{ OR } \\
\hline & Yes & No & COR & AOR \\
\hline \multicolumn{5}{|l|}{ Residence } \\
\hline Urban & 32 & 191 & 1 & 1 \\
\hline Rural & 49 & 128 & 2.31 (I.34,3.76) & I.7I (0.87, 3.39) \\
\hline \multicolumn{5}{|l|}{ Gestational age } \\
\hline$<37$ & 3 & 24 & $0.61(0.18,2.11)$ & $0.68(0.15,3.08)$ \\
\hline $37-42$ & 53 & 260 & I & 1 \\
\hline$>42$ & 18 & 9 & $2.45(1.05,5.76)$ & $3.81(0.92,15.88)$ \\
\hline Unknown & 16 & 17 & $4.62(2.19,9.71)$ & $5.83(2.37,14.31)^{*}$ \\
\hline \multicolumn{5}{|l|}{ Labor augmentation } \\
\hline Yes & 16 & 38 & $3.40(1.68,6.67)$ & $3.14(1.49,6.57)^{*}$ \\
\hline No & 33 & 263 & 1 & 1 \\
\hline \multicolumn{5}{|l|}{ Induction of labor } \\
\hline Yes & 13 & 16 & $3.62(1.66,7.88)$ & $1.73(0.24,12.70)$ \\
\hline No & 68 & 303 & & \\
\hline \multicolumn{5}{|l|}{ History of PIH } \\
\hline Yes & 17 & 24 & $3.27(1.65,6.43)$ & $3.10(1.23,7.83)^{*}$ \\
\hline No & 64 & 295 & 1 & 1 \\
\hline \multicolumn{5}{|l|}{ Birth weight } \\
\hline$<2500 \mathrm{gm}$ & 8 & 34 & $0.99(0.44,2.24)$ & $1.70(0.65,4.48)$ \\
\hline $2500-3999 \mathrm{gm}$ & 67 & 282 & 1 & 1 \\
\hline$\geq 4000 \mathrm{gm}$ & 6 & 3 & $8.42(2.05,34.52)$ & $11.00(2.30,57.51)^{*}$ \\
\hline
\end{tabular}

Note: Significant codes: $*<0.05$.

Consistent with the study done in Saudi Arabia, ${ }^{22}$ the most frequent indication of primary CS observed in this study was non-reassuring fetal heartbeat pattern (NRFHRP). This could be due to the individual and subjective decisions of CS without using fetal scalp PH. Giving attention for conservative management and implementing standard labor management strategies reduce primary cesarean section rate without compromising maternal and fetal safety. ${ }^{23}$ It was found that there was a $32 \%$ reduction in the cesarean section rate for fetal distress after the introduction of fetal blood sampling, ${ }^{24}$ unfortunately, this technique was not available in our study setting, whereas for the study done in Saudi Arabia, it might be because of use EFM.

Like the study in Maryland, ${ }^{25}$ women who were augmented were 3.14 times more susceptible to undergone primary cesarean section than those who were augmented. This result might be because of the wrong diagnosis of true labor and improper storages of uterotonic drugs. This can be supported by a study that shows oxytocic drug infusions lead to fetal distress and dysfunctional labor when given in false labor or the latent phase of labor. ${ }^{26}$ Induction of labor for nulliparous women with unfavorable cervix was associated with a 3.5 -fold increased risk of cesarean section compared with those women with spontaneous onset of labor. ${ }^{27}$ During Induction, unforeseen CPD can lead to obstructed labor and there might be uterine hyperstimulation which leads to NRFHR. ${ }^{15,28,29}$ Women who had a history of pregnancy-induced hypertension were 3.1 times more likely to undergo primary cesarean sections than those who had not. This observation might be because of pregnancy-induced hypertension is common in extremities of age ( $>40$ or $<18$ years). Additionally, women with medical comorbidities, higherorder pregnancy and it is associated intrauterine growth restriction and abruption placentae are also more likely to undergo $\mathrm{CS}^{3}$

This study also found the association of primary cesarean section rates with gestational age. Women whose gestational age was unknown were 5.83 times more likely to had primary cesarean section than those whose gestational age was between 37 and 42 weeks. Obstetric practitioners may try to avoid risk of maternal and fetal complications and conduct CS for women who had unknown gestational age.

Women with a neonatal birth weight of 4000 grams and above were 11 times more likely to had primary cesarean sections than those with neonatal birth weight of between 2500 and 4000 grams. Big baby more than $4000 \mathrm{gm}$ is associated with CPD, which is an indication for a cesarean section.

\section{Limitations}

This study was conducted based on secondary data. The use of primary data from clients would have helped to explore other factors that could not be found in the charts.

\section{Conclusion}

The magnitude of primary cesarean section in this study was high. The common indications were NRFHRP (32.1\%), CPD (18.5\%) and abnormal presentation (12.4\%). Birth weight, gestational age, PIH, and augmentations of labor were factors significantly associated with primary CS. Health care workers should have time for conservative management of NRFHRP rather than rushing to operational decisions. 


\section{Abbreviations}

COR, Crude Odds ratio; AOR, Adjusted Odds ratio; CPD, Cephalopelvic disproportion; CS, Cesarean section; DM, Diabetes mellitus; END, Early neonatal death; EFM, Electronic fetal monitoring; EFW, Estimated fetal weight; IUGR, Intra-Uterine growth restriction; IUFD, Intra Uterine Fetal death; PIH, Pregnancy-Induced Hypertension; SD, Standard Deviation; SVD, Spontaneous vaginal delivery; NRFHRP, non-reassuring fetal heart rate pattern; WHO, World Health Organization; VBAC, Vaginal birth after Cesarean section.

\section{Data Sharing Statement}

All data of this study are contained and presented in this document.

\section{Ethical Approval and Consent to Participate}

As this study used patient's cards to collect data, patients consent to review their cards was not required. However, we have obtained ethical approval and permission from Mekelle University, College of Health Sciences ethical review committee and Suhul Hospital administration body. We assured that this study was conducted in accordance with Declaration of Helsinki. Patient data were treated with utmost confidentiality.

\section{Acknowledgment}

We would like to acknowledge to the administrative staff of Suhul Hospital who permitted us to collect the data. We also acknowledge Getachew Mullu for his great contribution to editing and correcting the language problems in this manuscript.

\section{Author Contributions}

Both authors had substantial contributions to conception and design, acquisition of data, analysis, and interpretation of data; participated in drafting and revising the manuscript critically for intellectual content; gave final version to be published; and agree to be accountable for all aspects of the work.

\section{Funding}

The cost for this study was covered by Mekelle University.

\section{Disclosure}

The authors report no conflicts of interest in this work.

\section{References}

1. Daniel S, Viswanathan M, Simi BN, Nazeema A. Study of maternal outcome of emergency and elective caesarean section in a semi-rural tertiary hospital. Natl J Med Res. 2014;4(1):14.

2. Medicine AOF. iMedPub journals prevalence and outcome of caesarean section in Attat Hospital, Gurage Zone, SNNPR, Ethiopia Abstract. Arch Med. 2015;7(4):4-9.

3. Vega ES. Rising trends of cesarean section worldwide: a systematic review. Obstet Gynecol Int J. 2015;3(2). doi:10.15406/ogij.2015. 03.00073

4. Bayou YT, Mashalla YJS, Thupayagale-Tshweneagae G. Patterns of cesarean-section delivery in Addis Ababa, Ethiopia. Afr J Prim Health Care Fam Med. 2016;8(2):1-6.

5. Betran AP, Torloni MR, Zhang JJ, Gülmezoglu AM. WHO statement on cesarean section rates. BJOG. 2016;123(5):667-670. doi:10.1111/ 1471-0528.13526

6. Soren R, Maitra N, Patel PK, Sheth T. Elective versus emergency caesarean section: maternal complications and neonatal outcomes. IOSR J Nurs Health Sci. 2016;5(5):2320.

7. Rajbhanadary S, Shrivastava VR. Study of indications and post-operative complications of primary cesarean section in tertiary care hospital in Nepal. Int J Reprod Contracept Obstet Gynecol. 2018;7(3):835. doi:10.18203/2320-1770.ijrcog20180519

8. Abebe Eyowas F, Kidane Negasi A, Eyassu Aynalem G, Gebeyehu Worku A, Dadi AF. Adverse birth outcome: a comparative analysis between cesarean section and vaginal delivery at Felegehiwot Referral Hospital, Northwest Ethiopia: a retrospective record review [Corrigendum]. Pediatric Health Med Ther. 2016;7:129-130.

9. Begum T, Rahman A, Nababan H, et al. Indications and determinants of cesarean section delivery: evidence from a population-based study in Matlab, Bangladesh. PLoS One. 2017;12(11):1-16. doi:10.1371/ journal.pone. 0188074

10. Abebe FE, Gebeyehu AW, Kidane AN, Eyassu GA. Factors leading to cesarean section delivery at Felegehiwot referral hospital, Northwest Ethiopia: a retrospective record review. Reprod Health. 2016;13(1):1-7. doi:10.1186/s12978-015-0114-8

11. Kayawa Monglo EN. The effect of primary cesarean section on subsequent delivery. J Pregnancy Child Health. 2015;02(01):127-130.

12. Kuzma T. O-OBS-JM-014 Caesarean Sections in a National Referral Hospital in Addis Ababa, Ethiopia: trends, Predictors, and Outcomes. J Obstet Gynaecol Can. 2017;39(5):394. doi:10.1016/j.jogc.2017.03.043

13. Gebremedhin S. Trend and socio-demographic differentials of Caesarean section rate in Addis Ababa, Ethiopia: analysis based on Ethiopia demographic and health surveys data. Reprod Health. 2014;11(1):1-6. doi:10.1186/1742-4755-11-14

14. McCants BM, Greiner JR. Prebirth Education and Childbirth Decision Making. Int J Childbirth Educ. 2016;31(1)

15. Caughey AB, Cahill AG, Guise J-M, Rouse DJ. Gynecologists AC of $\mathrm{O}$ and. Safe prevention of the primary cesarean delivery. Am J Obstet Gynecol. 2014;210(3):179-193. doi:10.1016/j.ajog.2014.01.026

16. Minkoff $\mathrm{H}$, Chervenak FA. Elective primary cesarean delivery. N Engl J Med. 2003;348(10):946-950. doi:10.1056/NEJMsb022734

17. Ryding EL, Wijma K, Wijma B. Emergency cesarean section: 25 women's experiences. J Reprod Infant Psychol. 2000;18(1):33-39. doi:10.1080/02646830050001663

18. Guan P, Tang F, Sun G, Ren W. Prediction of emergency cesarean section by measurable maternal and fetal characteristics. $J$ Investig Med. 2020;68(3):799-806. doi:10.1136/jim-2019-001175

19. Vidic Z, Blickstein I, Štucin Gantar I, Verdenik I, Tul N. Timing of elective cesarean section and neonatal morbidity: a population-based study. J Matern Neonatal Med. 2016;29(15):2460-2462.

20. Kennedy CE, Yeh PT, Pandey S, Betran AP, Narasimhan M. Elective cesarean section for women living with HIV: a systematic review of risks and benefits. AIDS. 2017;31(11):1579. doi:10.1097/QAD.0000 000000001535 
21. Graham EM, Petersen SM, Christo DK, Fox HE. Intrapartum electronic fetal heart rate monitoring and the prevention of perinatal brain injury. Obstet Gynecol. 2006;108(3 Pt 1):656-666. doi:10.1097/01. AOG.0000230533.62760.ef

22. Alshwameen M, Albalawi M, Almutairi S, Shaman FA. Patient's attitude and preference towards medical students involvement in their health care in Tabuk region in Saudi Arabia. HAMDAN Med J. 2015;8(4)

23. Tehseen S. Reducing the rate of primary cesarean sections-an audit. J Pak Med Assoc. 2008;58:444.

24. Gangwar R, Chaudhary S. Caesarean Section for Foetal Distress and Correlation with Perinatal Outcome. J Obstet Gynecol India. 2016;66 (1):177-180. doi:10.1007/s13224-015-0831-5

25. Declercq E, MacDorman M, Osterman M, Belanoff C, Iverson R. Prepregnancy obesity and primary cesareans among otherwise lowrisk mothers in 38 US states in 2012. Birth. 2015;42(4):309-318.

26. Article O. Factors leading to increased cesarean. Gomal J Med Sci. 2008;6(1):1-5.
27. Amjad A, Amjad U, Zakar R, Usman A, Zakar MZ, Fischer F. Factors associated with caesarean deliveries among child-bearing women in Pakistan: secondary analysis of data from the Demographic and Health Survey, 2012 - 13. BMC Pregnancy Childbirth. 2018;18:1-9. doi:10.1186/s12884-018-1743-z

28. Thorsell M, LYRENÄS S, Andolf E, Kaijser M. Induction of labor and the risk for emergency cesarean section in nulliparous and multiparous women. Acta Obstet Gynecol Scand. 2011;90(10):1094-1099. doi:10.1111/j.1600-0412.2011.01213.x

29. Zhang J, Troendle J, Reddy UM, et al. Contemporary cesarean delivery practice in the United States. Am J Obstet Gynecol. 2010;203(4):326-e1. doi:10.1016/j.ajog.2010.06.058
Open Access Surgery

\section{Publish your work in this journal}

Open Access Surgery is an international, peer-reviewed, open access journal that focuses on all aspects of surgical procedures and interventions. Patient care around the peri-operative period and patient outcomes post-surgery are key topics for the journal. All grades of surgery from minor cosmetic interventions to major surgical procedures are covered. Novel techniques and the utilization of new

Submit your manuscript here: https://www.dovepress.com/open-access-surgery-journal

\section{Dovepress}

instruments and materials, including implants and prostheses that optimize outcomes constitute major areas of interest. The manuscript management system is completely online and includes a very quick and fair peer-review system, which is all easy to use. Visit http://www.dovepress.com/testimonials.php to read real quotes from published authors. 